\title{
Natural killer cell activity is a risk factor for the recurrence risk after curative treatment of hepatocellular carcinoma
}

\author{
Han Ah Lee ${ }^{1,2 \dagger}$, Hyun Gil Goh ${ }^{1 \dagger}$, Young-Sun Lee ${ }^{1}$, Young Kul Jung ${ }^{1}$, Ji Hoon Kim', Hyung Joon Yim', \\ Min-Goo Lee ${ }^{3}$, Hyunggin An ${ }^{4}$, Yoon Tae Jeen ${ }^{1}$, Jong Eun Yeon ${ }^{1}$, Kwan Soo Byun ${ }^{1}$ and Yeon Seok Seo ${ }^{*}$
}

\begin{abstract}
Background: Natural killer (NK) cells have been known to contribute to surveillance and control of hepatocellular carcinoma (HCC). However, the association of NK cell activity with stage and recurrence risk of HCC have not been fully evaluated.

Methods: Untreated patients with newly diagnosed HCC were prospectively enrolled. Peripheral blood mononuclear cells were isolated at the time of diagnosis. Patients who had undergone surgery or radiofrequency ablation were classified as the curative treatment group, and their blood samples were collected again at 1 month after treatment.

Results: A total of 80 patients with HCC were enrolled. The mean age was 62.5 years. At baseline, interferon (IFN)- $\gamma$ producing NK cell proportion was significantly lower in patients with Barcelona clinic liver cancer (BCLC) stage B, $C$, or $\mathrm{D}$ than in those with $\mathrm{BCLC}$ stage $0(42.9 \%$ vs. $56.8 \%, P=0.045)$. Among all patients, 56 patients had undergone curative treatment, and 42 patients re-visited at 1 month after curative treatment. There was no significant change in total NK cell and IFN- $\gamma$ producing NK cell proportion from baseline to 1 month after treatment (all $P>0.05$ ). During a median follow-up of 12.4 months, HCC recurred in 14 patients (33.3\%). When patients were classified according to the IFN- $\gamma$ producing NK cell proportion (group 1, $\geq 45 \%$; and group $2,<45 \%$ ), HCC recurrence rate did not differ according to the IFN- $\gamma$ producing NK cell proportion at baseline (log-rank test, $P=0.835$ ). However, patients with $<45 \%$ IFN- $\gamma$ producing NK cell proportion at 1 month after treatment had a significantly higher HCC recurrence rate than patients with that of $\geq 45 \%$ (log-rank test, $P<0.001$ ). Multivariate analysis revealed that $B C L C$ stage $B$ (hazard ratio $[H R]=3.412$, $P=0.045)$ and $<45 \%$ IFN- $\gamma$ producing NK cell proportion at 1 month after treatment $(H R=6.934, P=0.001)$ independently predicted an increased risk of HCC recurrence.
\end{abstract}

Conclusions: Decreased NK cell activity is significantly associated with the advanced stage of HCC, and the increased recurrence risk of HCC after curative treatment.

Keywords: Natural killer cell, Interferon- $\gamma$, Hepatocellular carcinoma, Stage, Recurrence

*Correspondence: drseo@korea.ac.kr

${ }^{\dagger}$ Han Ah Lee and Hyun Gil Goh equally contributed to this work as co-first authors

1 Department of Internal Medicine, Korea University College of Medicine,

73, Goryeodae-ro, Seongbuk-Gu, Seoul, Korea

Full list of author information is available at the end of the article

\section{Background}

Hepatocellular carcinoma (HCC) is currently the second leading cause of cancer-related mortalities worldwide [1], and have poor prognosis with high recurrence rate even in patients with early stage HCC treated with curative modality [2-5]. Since recurrence of HCC is the main cause of mortality [6, 7], identifying significant 
predictors for recurrence and stratifying risk of recurrence are important in managing patients with HCC.

Because most tumors arise in hepatic inflammation and consequent fibrosis, HCC appears as an inflammation-associated malignancy, characterized by infiltration of diverse immune cells [8-11]. It has been indicated that immune cells in the tumor microenvironment play a critical role in defense against HCC progression [12, 13]. The first host defense against tumor is innate immunity, and the liver contains a substantial number of various innate lymphocytes including natural killer (NK) cells $[14,15]$. NK cells account for a large proportion of innate lymphocytes, and are significantly involved in innate and adaptive immunological defense against cancer development [16].

Naturally, NK cells contribute to surveillance and control of HCC, capable of killing cancer cells. However, NK cells lose their function in the tumor microenvironment via various mechanisms: attenuation of absolute numbers, defective cytokine secretion, abnormal expression of NK cell receptors, and inhibition of NK cells by other immunoregulatory cells [17]. Dysfunction of NK cells has been suggested as an important mechanism for evasion of tumor cells [18]. Accordingly, several studies have suggested the relationship between multiplicity and function of NK cells and prognosis of patients with HCC [19-22]. Furthermore, previous studies in patients with chronic hepatitis $\mathrm{C}$ and hematologic malignancy showed that the function of NK cells recovered after antiviral therapy or chemotherapy, and the recovery of NK cell activity was correlated with improved prognosis [23-26]. However, because of only a limited number of studies have assessed the number and function of NK cells after treatment, the changes and significance of NK cell activity after curative treatment have not been fully evaluated.

Thus, we performed this study with untreated patients with newly diagnosed HCC based on the following hypotheses: (1) NK cell activity at diagnosis would be significantly associated with the stage of HCC. (2) NK cell activity may be altered after curative treatment in some patients with HCC. 3) NK cell activity after curative treatment may be an independent predictor for prognosis in HCC patients. A better understanding of these issues would contribute to the development of successful immunotherapies and selection of patients with unrestored immune function, who are indicated to have immunologic treatment after curative treatment of HCC.

In summary, we recruited patients with newly diagnosed HCC and assessed the proportion and activity of NK cells before and after curative treatment. In addition, we investigated the association of NK cell activity with HCC stage and the recurrence after curative treatment.

\section{Methods}

\section{Patients and specimens}

Untreated patients with newly diagnosed HCC were prospectively enrolled between 2016 and 2018 from Korea University Medical Center. The exclusion criteria were (1) age < 18 years; (2) history of HCC or organ transplant; (3) history of HCC treatment; (4) use of immunosuppressive agents; and (5) any other significant medical illness. Finally, a total of 90 patients were eligible and followed until September 2019. Patients were divided into two groups according to the treatment modality: (1) patients treated with surgical resection or radiofrequency ablation (RFA) (curative treatment group) and (2) patients treated with therapies other than resection or RFA, including best supportive care (conservative treatment group) (Additional file 1: Fig. 1).

Peripheral blood samples were obtained from all enrolled patients at the time of diagnosis. Among the 90 enrolled patients, 10 patients were excluded from the final analysis because of poor quality of peripheral mononuclear cells (PBMCs). Patients in the curative treatment group re-visited our clinic at 1 month after curative treatment, and their blood samples were collected again. Heparin tubes (BD Biosciences, Franklin Lakes, NJ, USA) were used to collect blood samples.

\section{Isolation of mononuclear cells from peripheral blood and tissues}

PBMCs were isolated from collected blood by Ficoll density gradient centrifugation (Biochrom, Berlin, Germany) as previously described $[27,28]$. The mononuclear cells were washed and resuspended in medium supplemented with $1 \%$ heat-inactivated fetal calf serum (BD Biosciences) for fluorescent-activated cell sorter (FACS) analysis.

\section{Flow cytometry analysis}

Leukocytes were stained with surface markers, fixed, permeabilized with IntraPre Reagent (Beckman Coulter, Fullerton, CA, USA), and further stained with the following antibodies against intracellular markers: anti-CD3 monoclonal antibody (mAb), anti-CD56 mAb, and antiIFN- $\gamma$ mAb (BD Biosciences). The FlowJo software program (version 10, FLOWJO, BD Biosciences) was used for data analysis. For the measurement of intracellular cytokine production, cells were stimulated at $37{ }^{\circ} \mathrm{C}$ for $5 \mathrm{~h}$ with Leukocyte Activation Cocktail (BD Biosciences) before staining, as previously described [29]. When we checked cell viability after thawing of frozen cells, the viability were good with more than $75 \%$. Cell viabilities were approximately checked $65 \%$ using dead cell marker. (Additional file 2: Fig. 2). We analyzed IFN- $\gamma$ positive NK cell population and the gating process was summarized 
at Fig. 1A. Finally, T-cell producing IFN- $\gamma$ was analyzed (Additional file 3: Fig. 3).

\section{Clinical evaluation and follow-up}

The index date was defined as the date of HCC diagnosis. Diagnosis of HCC was based on non-invasive criteria and/or pathology in cirrhotic patients, and pathology in non-cirrhotic patients. Non-invasive criteria were based on the identification of typical hallmarks of HCC, obtained by multiphasic computed tomography $(\mathrm{CT})$ or multiphase magnetic resonance imaging (MRI) (nodule $>1 \mathrm{~cm}$ with arterial hypervascularity and portal/ delayed-phase washout) [30-32]. Liver cirrhosis was diagnosed when typical ultrasonographic findings were found, together with a low platelet count $(<100,000 / \mu \mathrm{L})$, varices, or overt complication of cirrhosis [33].

\section{Treatment and recurrence surveillance after curative} treatment

The treatment type was determined by the clinician based on the clinical practice guideline for HCC in Korea [34]. In patients in the curative treatment group, treatment response was evaluated at 1 month after treatment, and complete response was defined as the disappearance of any intratumoral arterial enhancement in all target lesions, as evaluated by multiphasic CT scan or MRI at 1 month after treatment [35]. Patients that underwent curative treatment were surveilled periodically after treatment. Surveillance for recurrence was performed using imaging techniques, such as multiphasic CT scan or MRI and blood tests including tumor markers. Owing to the lack of evidence-based guidelines for recurrence surveillance, screening was conducted every 1-6 months as per the clinician's decision.

\section{Outcomes}

The primary outcome was the recurrence of HCC. The secondary outcome was the stage of $\mathrm{HCC}$ at diagnosis. Intrahepatic HCC recurrence was defined by the same criteria applied for initial HCC diagnosis. Extrahepatic recurrence was evaluated by $\mathrm{CT}$ or bone scan performed at the discretion of the clinician. Barcelona clinic liver cancer (BCLC) staging system was used for HCC staging [36].

\section{Statistical analysis}

Results are expressed as means \pm standard deviations or numbers with percentages. The statistical significance of differences between continuous and categorical variables was examined by Student's $t$-test (or the MannWhitney test, when appropriate) and the chi-squared test (or Fisher's exact test, when appropriate), respectively. The cumulative incidences of HCC recurrence were calculated using the Kaplan-Meier method with

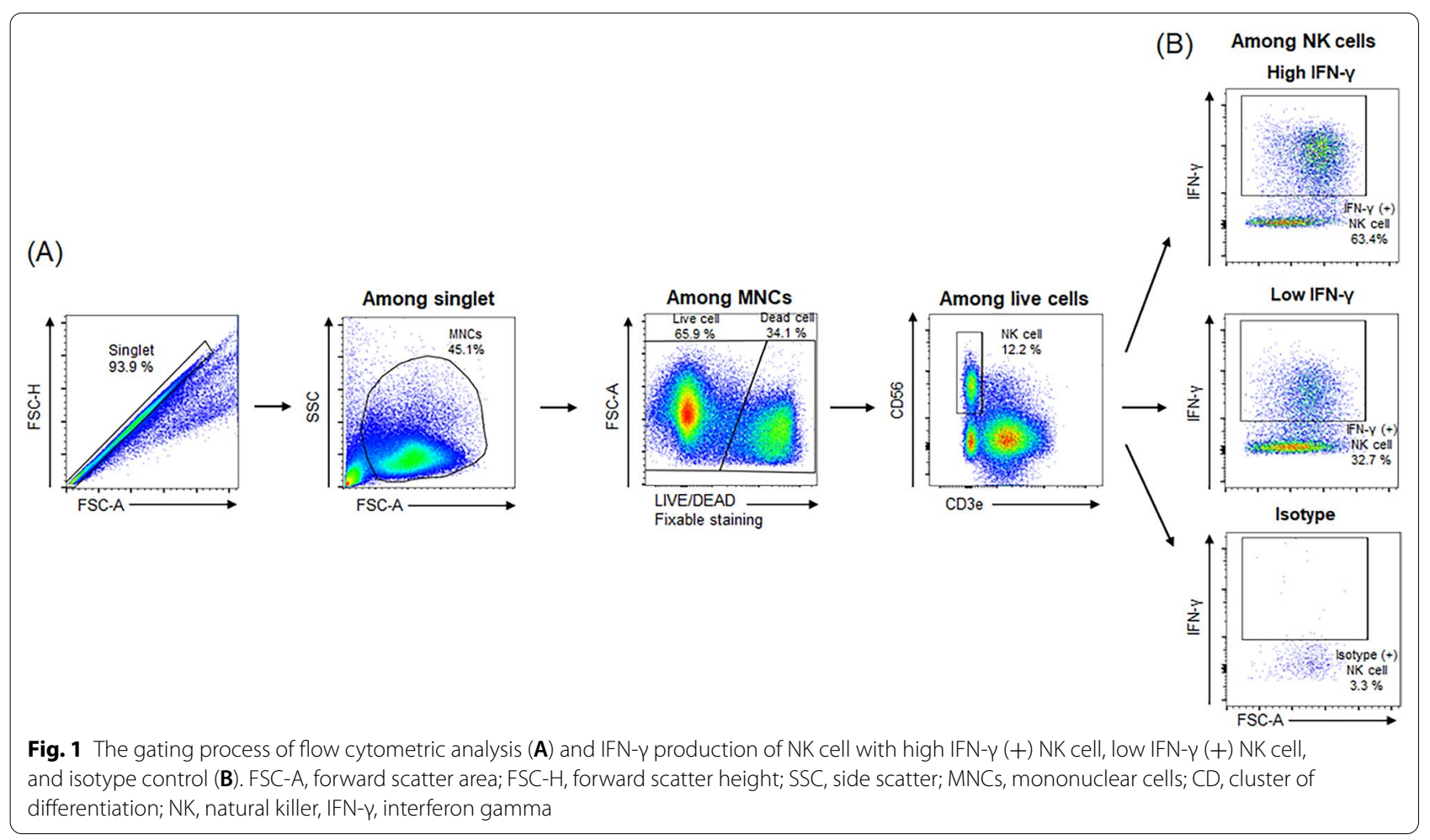


time-to-progression. These incidences were compared among subgroups of the study population defined based on the NK cell profile using the log-rank test. Multivariate analyses were performed to identify independent predictors of HCC recurrence using the Cox proportional hazards model. SPSS statistical software (version 13.0) was used for all statistical analyses. All data were analyzed using two-tailed tests unless otherwise specified, and $P<0.05$ was considered statistically significant.

\section{Results}

\section{Baseline characteristics of the study population}

A total of 80 patients were finally selected for the statistical analysis (Additional file 1: Fig. 1). The baseline characteristics of the study population are presented in Table 1. The mean age of the patients was $62.5(56.0-70.0)$ years, and 60 patients $(75.0 \%)$ were men. Chronic hepatitis B virus (HBV) infection was the most frequent underlying liver disease (48 patients, 60.0\%). Liver cirrhosis was combined in 64 patients $(80.0 \%)$. Because of the small numbers of patients in BCLC stage $C$ and $D$, patients were classified into 3 groups: BCLC 0 , patients with BCLC stage $0(\mathrm{n}=15,18.8 \%)$; BCLC A, patients with BCLC stage A $(n=38,47.5 \%)$; and BCLC BCD, patients with BCLC stage B, C, or D (27 patients, 33.8\%).

\section{IFN- $\gamma$ producing NK cell proportion significantly decreased in advanced-stage $\mathrm{HCC}$}

As shown in Fig. 2A, the total NK cell proportion was significantly higher in patients with BCLC BCD than in those with BCLC A (12.4\% vs. $8.6 \%, P=0.046)$. IFN- $\gamma$ producing NK cell proportion was significantly lower in patients with BCLC BCD than in those with BCLC 0 (42.9\% vs. $56.8 \%, P=0.045)$, and there was a trend of lower IFN- $\gamma$ producing NK cell proportion in patients with BCLC BCD than in those with BCLC A $(42.9 \%$ vs. $52.6 \%, P=0.080$ ) (Fig. $2 \mathrm{~B}$ ). There were no statistical differences in T-cell producing IFN- $\gamma$ proportion

Table 1 Baseline characteristics of the study population according to the BCLC stage

\begin{tabular}{|c|c|c|c|c|}
\hline Variables & All patients $(n=80)$ & $\operatorname{BCLC} 0(n=15,18.8 \%)$ & $\mathrm{BCLC} A(n=38,47.5 \%)$ & $\operatorname{BCLC~BCD~}(n=27,33.7 \%)$ \\
\hline Age, years & $62.5(56.0-70.0)$ & $63.3(58.5-69.0)$ & $64.2(57.5-71.0)$ & $59.6(53.0-66.5)$ \\
\hline Male gender & $60(75.0)$ & $10(66.7)$ & $30(78.9)$ & $20(74.1)$ \\
\hline \multicolumn{5}{|l|}{ Etiology } \\
\hline Hepatitis B virus & $48(60.0)$ & $9(60.0)$ & $20(52.6)$ & $19(70.4)$ \\
\hline Hepatitis C virus & $7(8.8)$ & $2(13.3)$ & $4(10.5)$ & $1(3.7)$ \\
\hline Alcohol & $13(16.2)$ & $1(6.7)$ & $9(23.7)$ & $3(11.1)$ \\
\hline Others & $12(15.0)$ & $3(20.0)$ & $5(13.2)$ & $4(14.8)$ \\
\hline Liver cirrhosis & $64(80.0)$ & $12(80.0)$ & $28(73.7)$ & $24(88.9)$ \\
\hline \multicolumn{5}{|l|}{ Child-Pugh class } \\
\hline A & $62(77.5)$ & $15(100)$ & $31(81.6)$ & $16(59.3)$ \\
\hline $\mathrm{B}$ or $\mathrm{C}$ & $18(22.5)$ & $0(0)$ & $7(18.4)$ & $11(40.7)$ \\
\hline Total bilirubin, mg/dL & $1.44(0.70-1.20)$ & $0.67(0.35-0.95)$ & $1.14(0.70-1.15)$ & $2.24(0.80-2.05)$ \\
\hline Albumin, g/dL & $3.9(3.4-4.3)$ & $4.0(3.5-4.5)$ & $3.9(3.5-4.5)$ & $3.7(3.4-4.1)$ \\
\hline Aspartate aminotransferase, IU/L & $70.7(33.0-80.0)$ & $48.9(23.5-56.0)$ & $48.1(31.0-59.5)$ & $111.8(54.5-126.5)$ \\
\hline Alanine aminotransferase, IU/L & $44.6(19.0-52.0)$ & $31.5(14.0-42.0)$ & $37.7(18.5-44.5)$ & $60.4(28.5-54.5)$ \\
\hline Platelet count, $10^{9} / \mathrm{L}$ & $144.8(97.0-181.0)$ & $126.9(76.0-155.0)$ & $144.8(87.5-195.0)$ & $154.1\left(116.5-185.0_{-}\right.$ \\
\hline Prothrombin time, INR & $1.12(1.03-1.17)$ & $1.08(0.99-1.14)$ & $1.11(1.01-1.20)$ & $1.14(1.04-1.22)$ \\
\hline Alpha-fetoprotein, ng/mL & $7620.9(4.4-439.8)$ & $91.0(2.4-61.2)$ & $3712.8(3.6-74.6)$ & $16,695.1(92.5-69,082.0)$ \\
\hline PIVKA-II, mAU/mL & $6918.1(18.0-649.0)$ & $32.9(58.5-69.0)$ & $506.9(57.5-71.0)$ & $18,961.3(53.0-66.5)$ \\
\hline \multicolumn{5}{|l|}{ Type of treatment } \\
\hline Resection & $31(38.8)$ & $7(46.7)$ & $18(47.4)$ & $6(22.2)$ \\
\hline Radiofrequency ablation & $25(31.2)$ & $6(40.0)$ & $18(47.4)$ & $1(3.7)$ \\
\hline Transarterial chemoembolization & $8(10.0)$ & $2(13.3)$ & $2(5.3)$ & $4(14.8)$ \\
\hline Sorafenib & $5(6.2)$ & $0(0)$ & $0(0)$ & $5(18.5)$ \\
\hline Radiation therapy & $1(1.2)$ & $0(0)$ & $0(0)$ & $1(3.7)$ \\
\hline Transarterial radioembolization & $3(3.8)$ & $0(0)$ & $0(0)$ & $3(11.1)$ \\
\hline Conservative treatment & $7(8.8)$ & $0(0)$ & $0(0)$ & $7(25.9)$ \\
\hline
\end{tabular}



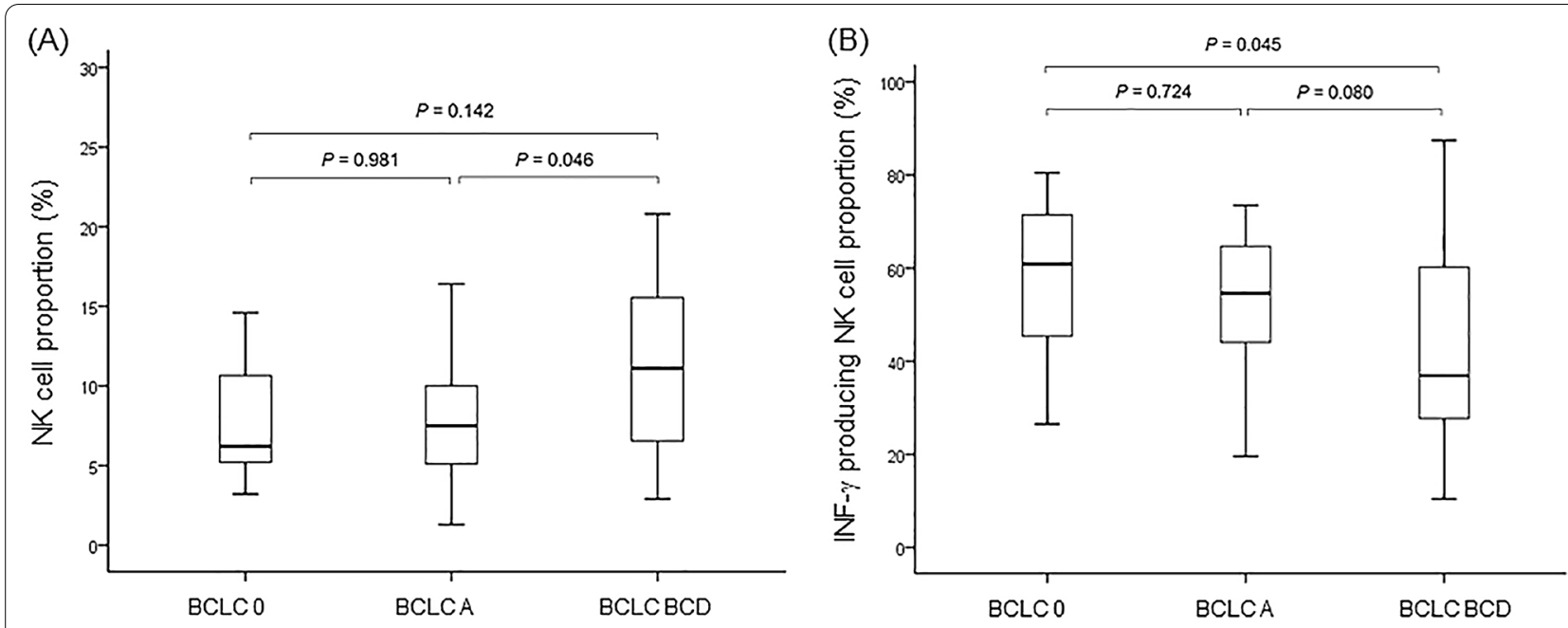

(C)

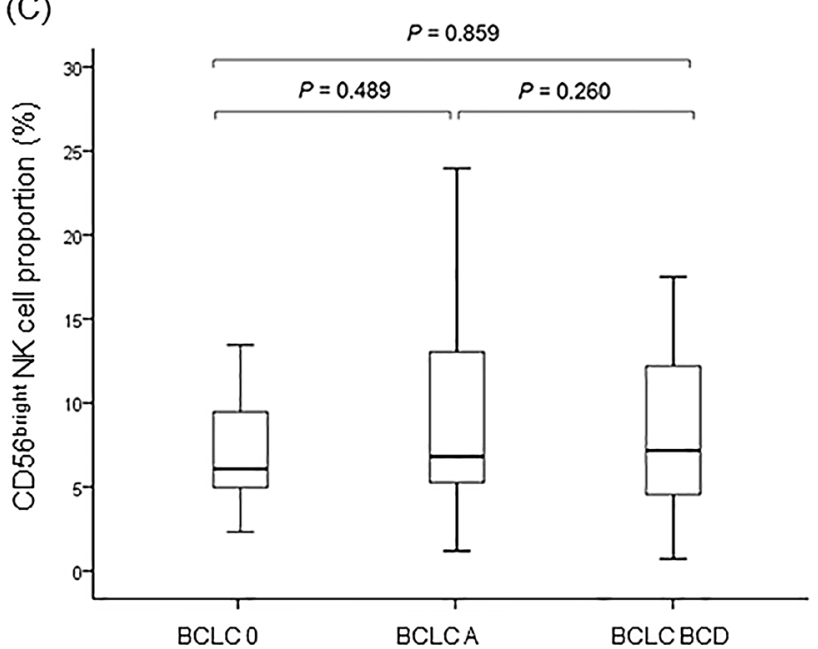

(D)

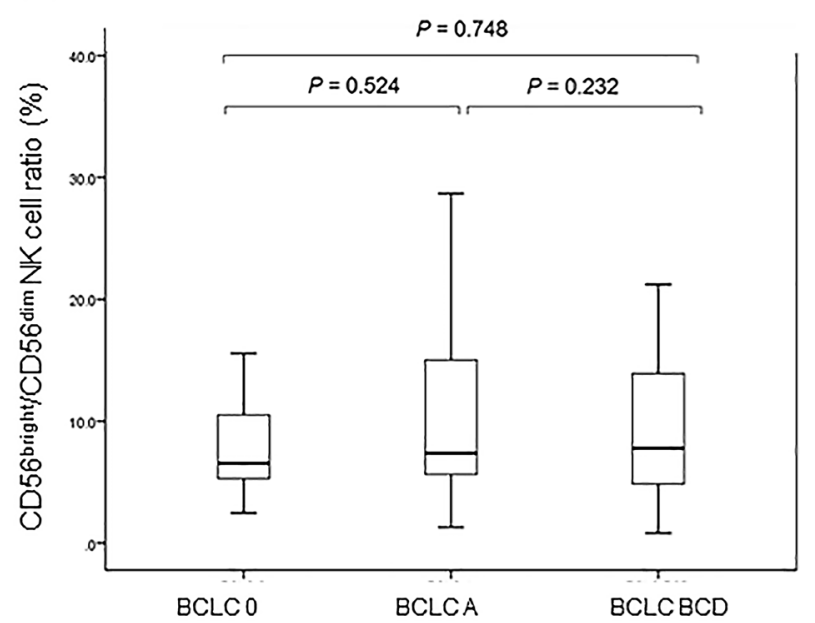

Fig. 2 NK cell proportion (A), IFN- $ү$ producing NK cell proportion (B), CD56 bright $N K$ cell proportion (C), and ratio of CD56 bright $N K$ cell and CD56 dim NK cell (D) according to the BCLC stage. NK, natural killer; IFN, interferon; BCLC, Barcelona clinic liver cancer; BCLC 0, patients with $B C L C$ stage 0; $B C L C A$, patients with $B C L C$ stage $A$; and $B C L C B C D$, patients with $B C L C$ stage $B, C$, or $D$

according to $\mathrm{BCLC}$ stages (all $\mathrm{P}>0.05$ ). CD56 $6^{\text {bright }} \mathrm{NK}$ cell proportion and ratio of $\mathrm{CD} 56^{\text {bright }} \mathrm{NK}$ cell and CD56 ${ }^{\mathrm{dim}}$ NK cell were comparable among all groups (all $P>0.05$ ) (Fig. 2C, D).

\section{Baseline characteristics of patients in the curative \\ treatment group}

Of the 56 patients in the curative treatment group, 42 patients re-visited at 1 month after curative treatment, and their blood samples were collected again. The baseline characteristics of the curative treatment group are presented in Table 2. There were 13 patients (31.0\%) in BCLC stage 0, 21 patients (50.0\%) in BCLC stage A, and 8 patients $(19.0 \%)$ in BCLC stage B. Patients were treated with surgical resection (28 patients, $66.7 \%)$ or RFA (14 patients, 33.3\%).

\section{NK cell profiles were not significantly changed after curative treatment}

There were no significant changes in total NK cell proportion (9.6\% vs. $11.2 \%, P=0.299)$ and IFN- $\gamma$ producing NK cell proportion $(50.5 \%$ vs. $45.1 \%, P=0.108)$ from baseline to 1 month after curative treatment (Additional file 4: Fig. 4). In addition, the proportions of CD56 ${ }^{\text {bright }}$ NK cell and CD56 ${ }^{\text {dim }}$ NK cells were also not significantly changed from baseline to 1 month after curative treatment (all $P>0.05$ ). 
Table 2 Characteristics of the population according to the post 1 month IFN- $\gamma$ producing NK cell proportion

\begin{tabular}{|c|c|c|c|c|}
\hline Variables & All patients $(n=42)$ & $\begin{array}{l}\text { Group 1, IFN- } \gamma \text { producing NK cell } \\
\text { proportion } \geq 45 \%(n=26,61.9 \%)\end{array}$ & $\begin{array}{l}\text { Group 2, IFN- }- \text { producing NK cell } \\
\text { proportion }<45 \%(n=16,38.1 \%)\end{array}$ & $P$ value \\
\hline Age, years & $62.6(65.5-68.3)$ & $62.5(56.3-68.5)$ & $62.1(55.8-68.8)$ & 0.889 \\
\hline Male gender & $29(69.0)$ & $15(57.7)$ & $13(81.2)$ & 0.116 \\
\hline Etiology & & & & 0.082 \\
\hline Hepatitis B virus & $25(59.5)$ & $13(50.0)$ & $12(75.0)$ & \\
\hline Hepatitis C virus & $4(9.5)$ & $4(15.4)$ & $0(0.0)$ & \\
\hline Alcohol & $7(16.7)$ & $3(11.5)$ & $4(25.0)$ & \\
\hline Others & $6(14.3)$ & $6(23.1)$ & $0(0.0)$ & \\
\hline Liver cirrhosis & $32(76.2)$ & $19(73.1)$ & $13(81.2)$ & 0.546 \\
\hline Child-Pugh class & & & & 0.969 \\
\hline A & $34(81.0)$ & $21(80.8)$ & $13(81.2)$ & \\
\hline B & $8(19.0)$ & $5(19.2)$ & $3(18.8)$ & \\
\hline BCLC stage & & & & 0.897 \\
\hline 0 & $13(31.0)$ & $7(26.9)$ & $6(37.5)$ & \\
\hline A & $21(50.0)$ & $14(53.8)$ & $7(43.8)$ & \\
\hline B & $8(19.0)$ & $5(19.3)$ & $3(18.7)$ & \\
\hline Total bilirubin, mg/dL & $1.07(0.60-1.10)$ & $1.15(0.60-1.10)$ & $0.94(0.40-1.65)$ & 0.433 \\
\hline Albumin, $\mathrm{g} / \mathrm{dL}$ & $4.1(3.7-4.5)$ & $4.1(3.6-4.5)$ & $4.1(3.6-4.6)$ & 0.796 \\
\hline Aspartate aminotransferase, IU/L & $50.0(25.0-61.5)$ & $53.9(26.8-62.3)$ & $40.6(24.0-60.0)$ & 0.206 \\
\hline Alanine aminotransferase, IU/L & $37.1(19.0-51.0)$ & $39.5(19.0-56.8)$ & $28.6(17.0-40.0)$ & 0.098 \\
\hline Platelet count, $10^{9} / \mathrm{L}$ & $147.5(87.5-195.0)$ & $145.2(81.5-210.8)$ & $155.9(89.5-183.5)$ & 0.598 \\
\hline Prothrombin time, INR & $1.09(1.00-1.16)$ & $1.13(1.05-1.16)$ & $1.06(0.99-1.17)$ & 0.192 \\
\hline Alpha-fetoprotein, $\mathrm{ng} / \mathrm{mL}$ & $3293.4(3.6-72.0)$ & $40,702.0(3.8-63.7)$ & $1003.8(3.4-481.1)$ & 0.546 \\
\hline PIVKA-II, mAU/mL & $992.5(14.0-102.0)$ & $621.2(14.0-79.3)$ & $1678.2(16.5-264.0)$ & 0.432 \\
\hline Type of treatment & & & & 0.822 \\
\hline Resection & $28(66.7)$ & $17(65.4)$ & $11(68.8)$ & \\
\hline Radiofrequency ablation & $14(33.3)$ & $9(34.6)$ & $5(31.2)$ & \\
\hline
\end{tabular}

Variables are expressed as mean (interquartile range) or $\mathrm{n}$ (\%). BCLC Barcelona clinic liver cancer, IFN interferon

\section{IFN- $\gamma$ producing NK cell proportion at 1 month after curative treatment significantly predicted $\mathrm{HCC}$ recurrence} Among 42 patients who re-visited at 1 month after curative treatment, HCC recurred in 14 patients (33.3\%) during the median follow-up of 12.4 months. $\mathrm{HCC}$ recurrence rates at $6,12,18$, and 24 months were $12.7 \%, 28.1 \%, 41.2 \%$, and $41.2 \%$, respectively. To investigate the clinical significance of NK cell activity in $\mathrm{HCC}$ recurrence, patients were classified into 2 groups according to the IFN- $\gamma$ producing $\mathrm{NK}$ cell proportion as follows: group 1, patients with IFN- $\gamma$ producing NK cell proportion $\geq 45 \%$; and group 2 , patients with IFN- $\gamma$ producing NK cell proportion $<45 \%$ (Fig. 1B). The number of patients with $\geq 45 \%$ IFN- $\gamma$ producing NK cell proportion was $28(66.6 \%)$ at baseline, and 26 $(61.9 \%)$ at 1 month after treatment.

There was no significant difference in $\mathrm{HCC}$ recurrence rate between patients with $<45 \%$ IFN- $\gamma$ producing NK cell proportion at baseline and patients with that of $\geq 45 \%(P=0.835)$ (Fig. $3 \mathrm{~A})$. However, patients with $<45 \%$ IFN- $\gamma$ producing NK cell proportion at 1 month after treatment had a significantly higher HCC recurrence rate than patients with that of $\geq 45 \%$ $(P<0.001)$ (Fig. 3B). There were no other significant difference in baseline characteristics between patients in group 1 and 2 , according to the IFN- $\gamma$ producing NK cell proportion at 1 month after treatment (all $P>0.05$ ) (Table 2). Based on the striking positive association between IFN- $\gamma$ producing $\mathrm{NK}$ cell proportion at 1 month after curative treatment and HCC recurrence, further multivariate analysis revealed that BCLC stage $B$ (hazard ratio $[\mathrm{HR}]=3.412,95 \%$ confidence interval [CI] $1.026-11.355 ; P=0.045)$ and $<45 \%$ IFN- $\gamma$ producing NK cell proportion at 1 month after treatment (HR $=6.934,95 \%$ CI 2.100-22.897; $P=0.001)$ independently predicted an increased risk of HCC recurrence (Table 3). T-cell producing IFN- $\gamma$ proportion at baseline (HR 0.976, $P=0.448$ ), and 1 month after curative treatment (HR 0.949, $P=0.325$ ) were not associated with the risk of $\mathrm{HCC}$ recurrence. 

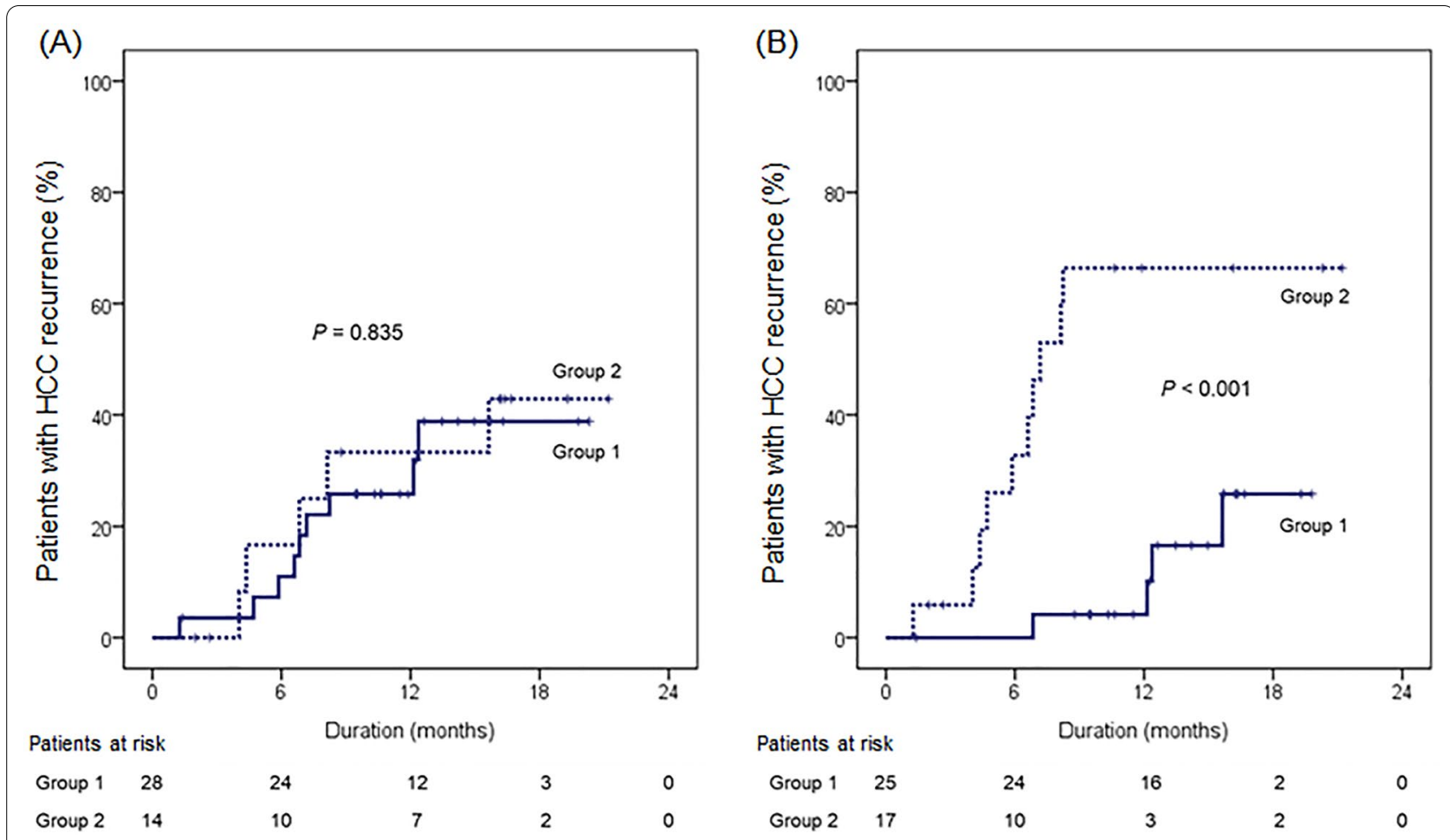

Fig. $3 \mathrm{HCC}$ recurrence rates among groups according to the IFN- $\gamma$ producing NK cell proportion at baseline (A) and 1 month after treatment (B). Group 1, patients with IFN- $\gamma$ producing NK cell proportion $\geq 45 \%$; Group 2, patients with IFN- $\gamma$ producing NK cell proportion $<45 \%$. HCC, hepatocellular carcinoma; IFN, interferon; NK, natural killer

Table 3 Predictors for HCC recurrence

\begin{tabular}{|c|c|c|c|c|c|}
\hline \multirow[t]{2}{*}{ Variable } & \multirow[t]{2}{*}{ Rating } & \multirow{2}{*}{$\begin{array}{l}\text { Univariate } \\
P \text { value }\end{array}$} & \multicolumn{3}{|c|}{ Multivariate } \\
\hline & & & $\mathrm{HR}$ & $95 \% \mathrm{Cl}$ & $P$ value \\
\hline Age & Years & 0.549 & & & \\
\hline Sex & $0=$ female $1=$ male & 0.497 & & & \\
\hline Etiology & $1=$ viral $; 2=$ other & 0.907 & & & \\
\hline Liver cirrhosis & $0=$ no; $1=$ yes & 0.0578 & & & \\
\hline Type of treatment & $1=$ resection; $2=$ RFA & 0.062 & & & \\
\hline Child-Pugh class & $1=A ; 2=B$ & 0.140 & & & \\
\hline BCLC stage & $1=0$ or $A ; 2=B$ & 0.035 & 3.412 & $1.026-11.355$ & 0.045 \\
\hline Total bilirubin, mg/dL & & 0.571 & & & \\
\hline Albumin, g/dL & & 0.301 & & & \\
\hline Aspartate aminotransferase, IU/L & & 0.163 & & & \\
\hline Alanine aminotransferase, IU/L & & 0.848 & & & \\
\hline Platelet count, $10^{9} / \mathrm{L}$ & & 0.120 & & & \\
\hline Prothrombin time, INR & & 0.296 & & & \\
\hline MELD score & & 0.766 & & & \\
\hline Alpha-fetoprotein, $\mathrm{ng} / \mathrm{mL}$ & & 0.329 & & & \\
\hline PIVKA-II, mAU/mL & & 0.117 & & & \\
\hline Baseline IFN- $\gamma$ producing NK cell proportion, $\%$ & $1=<45 \% ; 2=\geq 45 \%$ & 0.836 & & & \\
\hline${ }^{*}$ P1m IFN- $\gamma$ producing NK cell proportion, $\%$ & $1=<45 \% ; 2=\geq 45 \%$ & 0.001 & 6.934 & $2.100-22.897$ & 0.001 \\
\hline
\end{tabular}

${ }^{*} \mathrm{P} 1 \mathrm{~m}$, post 1 month after curative treatment; $H C C$ hepatocellular carcinoma, $H R$ hazard ratio, $C l$ confidence interval, $B C L C$ Barcelona clinic liver cancer, IFN interferon 


\section{Discussion}

Defects in NK cell functions have been suggested as important mechanisms for tumor development [37]. However, the association between NK cell dysfunction and $\mathrm{HCC}$ progression and recurrence has not been fully evaluated. Especially, little information is currently available regarding post-treatment NK cell function. This prospective study recruited untreated patients with newly diagnosed HCC, and investigated the clinical implication of peripheral blood NK cell activity in HCC stage and recurrence after curative treatment. Our results showed that IFN- $\gamma$ producing NK cell proportion significantly decreased in patients with intermediate and advanced-stage HCC than very early-stage HCC (42.9\% vs. $56.8 \%, P=0.045$ ). Patients with $<45 \%$ IFN- $\gamma$ producing NK cell proportion at 1 month after treatment exhibited a higher incidence of $\mathrm{HCC}$ recurrence than patients with that of $\geq 45 \%(P<0.001)$. Moreover, BCLC stage B or C $(\mathrm{HR}=3.412)$ and IFN- $\gamma$ producing NK cell proportion at 1 month after treatment $<45 \%(\mathrm{HR}=6.934)$ independently predicted an increased risk of $\mathrm{HCC}$ recurrence (all $P<0.05$ ). These findings indicate that $\mathrm{NK}$ cell activity decreases in advanced-stage $\mathrm{HCC}$, and patients with decreased NK cell activity at after curative treatment are at higher risk of HCC recurrence even after effective treatment.

Our study has several strengths and clinical implications. First, the association between peripheral blood NK cell activity HCC stage has not been fully clarified in previous studies $[19,20]$. In the present study, we observed that, although the total NK cell proportion was rather higher in patients with BCLC BCD than in those with BCLC A HCC $(P=0.046)$, the total IFN- $\gamma$ producing $\mathrm{NK}$ cell proportion was significantly lower in patients with BCLC BCD than in those with BCLC 0 $(P=0.045)$, and a trend of lower IFN- $\gamma$ producing NK cell proportion was observed in patients with BCLC $\mathrm{BCD}$ than in those with BCLC A $(P=0.080)$. These findings indicate that circulating NK cells lose their capacity to produce IFN- $\gamma$ in advanced HCC, hindering anti-tumor immune response in patients with $\mathrm{HCC}$, and these defects are aggravated with HCC progression regardless of the total NK cell number. It has been well known that NK cells play a major role in initiation and progression of HCC through various mechanisms including decreased frequency and defective cytokine secretion [38]. Cai et al. showed similar result with peripheral blood (IFN- $\gamma$ producing NK cell proportion of healthy controls vs. Chinese classification Stage I, II, or III, all $P<0.05$ ) [20]. However, patients in Chinese classification stage III had higher IFN- $\gamma$ producing NK cell proportion than those in stage I or II. This disparity may be caused by the difference in HCC staging system.
The Chinese classification system was developed in 1999 , and not has been widely used for HCC staging.

Second, we found that $<45 \%$ IFN- $\gamma$ producing NK cell proportion at 1 month after curative treatment was independently associated with an increased risk of $\mathrm{HCC}$ recurrence $(\mathrm{HR}=6.934)$. Interestingly, the IFN- $\gamma$ producing $\mathrm{NK}$ cell proportion at diagnosis had no significant association with $\mathrm{HCC}$ recurrence. This result indicates that restoration of NK cell activity after successful removal of tumor and related microenvironment may play a more critical role in HCC recurrence than decreased NK cell activity at baseline. Previous studies have only evaluated the relationship between NK cell activity at diagnosis and prognosis of patients with HCC. Taketomi et al. showed that $\leq 30 \%$ preoperative NK cell activity in PBMCs was independently associated with lower disease-free survival in patients with HCC $(P=0.0412)$ [19]. Although this study suggested important clinical implications, $34.1 \%$ of patients had portal vein invasion, and $38.9 \%$ of patients had intrahepatic metastasis. It is difficult to believe that hepatectomy could completely remove tumor burden in these patients. Wu et al. reported that the number of NK cells in the intratumoral region is an independent prognostic factor for both overall survival and disease-free survival [21]. The results of our study provide important novel insights not only into the necessity of serial monitoring of immune status in patients with HCC after curative treatment, but also into the rational design and selection of patients for novel immune-based anticancer therapies.

Third, we observed no significant difference in CD56 $6^{\text {bright }} \mathrm{NK}$ cell proportion and ratio of CD56 $6^{\text {bright }}$ NK cell and CD56 ${ }^{\text {dim }}$ NK cell among patients in various stages of HCC (all $P>0.05$ ), which is consistent with the findings of Wu et al. and Cai et al. [20, 21]. CD56 ${ }^{\mathrm{dim}} \mathrm{NK}$ cells, which represent mature phenotype of NK cells, mediate cytolytic reaction, in contrast, the immature CD56 ${ }^{\text {bright }}$ NK cells have been regarded to have cytokineproducing function. Because of the complex interaction between immune cells and cytokines, CD56 ${ }^{\text {bright }}$ NK cell proportion does not proportionally affect cytokine-producing function. Also, though it has been belived that CD56 ${ }^{\text {dim }}$ NK cell would decrease in tumor infiltrating lymphocyte compared to non-tumor-infiltrating lymphocyte, there have been conflicting results $[20,21]$.

We are also aware of several issues that need to be addressed. First, the sample size of this study is small. Further studies with larger number of patients would be needed to validate the results of our study. Second, although we revealed the clinical significance of peripheral blood IFN- $\gamma$ producing NK cell proportion in $\mathrm{HCC}$, further investigation of liver NK cells is needed to elucidate the immune reaction and specific mechanism 
involved in NK cell dysfunction. However, although the assessment of NK cell profile in liver tissues provides a more detailed evaluation, histological approach is not easily applicable in clinical setting, especially in serial assessment. Therefore, we assessed NK cell profiles in PBMCs because of the convenience and higher accessibility, and we believe that the results of this study would be helpful in clinical settings. Third, $68.8 \%$ of patients had HBV or HCV. It is well known that the status of viral hepatitis affects NK cell activity [39, 40], and this could be a confounding factor. Due to the small sample size, significant correlation between HBV DNA level and NK cell activity may not be found in this study $(r=0.055$, $P=0.737$ ). Lastly, $19.0 \%$ of patients in the curative treatment group were in BCLC stage B, who were not ideal for surgical resection or RFA in most guidelines. However, our findings still revealed that NK cell activity was a more potent predictor for HCC recurrence than HCC stage, and hence, are of great clinical significance.

Consequently, we showed that NK cell activity decreases in advanced-stage HCC. In addition, NK cell activity at 1 month after curative treatment was an independently predictor for increased risk of HCC recurrence. Therefore, serial monitoring of NK cell activity could be helpful in managing patients with HCC. Additionally, our findings could be of clinical importance in the development of novel immune-based anticancer therapies.

\section{Abbreviations \\ NK: Natural killer; PBMC: Peripheral blood mononuclear cell; HCC: Hepatocel- lular carcinoma; IFN: Interferon; BCLC: Barcelona clinic liver cancer; HR: Hazard ratio; RFA: Radiofrequency ablation; FACS: Fluorescent-activated cell sorter; mAb: Monoclonal antibody; CT: Computed tomography; MRI: Multiphase magnetic resonance imaging; HBV: Hepatitis B virus; $\mathrm{Cl}$ : Confidence interval.}

\section{Supplementary Information}

The online version contains supplementary material available at https://doi. org/10.1186/s12876-021-01833-2.

\section{Additional file 1: Figure 1. Flowchart of the patient population. HCC,} hepatocellular carcinoma; PBMC, peripheral blood mononuclear cell.

Additional file 2: Figure 2. FACS plots of patients. FACS, fluorescent-activated cell sorter; CD, cluster of differentiation.

Additional file 3: Figure 3. IFN- $\gamma$ production of T cell with high IFN- $\gamma(+)$ (A), low IFN- $\gamma(+)(B)$, and isotype control (C). FSC-A, forward scatter area; $C D$, cluster of differentiation; IFN- $\gamma$, interferon gamma.

Additional file 4: Figure 4. Baseline and 1 month after curative treatment NK cell proportion (A) and IFN- $\gamma$ producing NK cell proportion (B) of each patient. NK, natural killer, IFN- $\gamma$, interferon gamma.

\section{Acknowledgements}

We would like to thank Editage (www.editage.co.kr) for English language editing.

\section{Authors' contributions}

Y.S. Seo designed this study. H.A. Lee and H.G. Goh provided study materials and patients. H.A. Lee, H.G. Goh, Y. Lee, Y.K. Jung, J.H. Kim, H.J. Yim, M. Lee, H. An, Y.T. Jeen, J.E. Yeon, K.S. Byun collected and assembled data; H.A. Lee and H.G. Goh analyzed and interpreted data; All authors involved in manuscript writing. All authors read and approved the final manuscript.

\section{Funding}

This study was supported by the NKMAX@. The funders had no role in study design, data collection and analysis, decision to publish, or manuscript preparation.

\section{Availability of data and materials}

The datasets used and/or analyzed during the current study are available from the corresponding author on reasonable request.

\section{Declarations}

\section{Ethics approval and consent to participate}

The trial was conducted in accordance with the Declaration of Helsinki (as revised in 2013). The study was approved by institutional review board of Korea University Medical Center (ED16364) and informed consent was taken from all individual participants.

\section{Consent for publication}

Not applicable.

\section{Competing interests}

The authors have no conflicts of interest to declare.

\section{Author details}

${ }^{1}$ Department of Internal Medicine, Korea University College of Medicine, 73, Goryeodae-ro, Seongbuk-Gu, Seoul, Korea. ${ }^{2}$ Department of Internal Medicine, Sanggye Paik Hospital, Inje University College of Medicine, Seoul, Korea. ${ }^{3}$ Department of Physiology, Korea University College of Medicine, Seoul, Korea. ${ }^{4}$ Department of Biostatistics, Korea University College of Medicine, Seoul, Korea.

Received: 30 March 2021 Accepted: 24 May 2021

Published online: 12 June 2021

\section{References}

1. Akinyemiju T, Abera S, Ahmed M, et al. The burden of primary liver cancer and underlying etiologies from 1990 to 2015 at the global, regional, and national level: results from the global burden of disease study 2015. JAMA Oncol. 2017;3:1683-91.

2. Arii S, Tanaka J, Yamazoe Y, et al. Predictive factors for intrahepatic recurrence of hepatocellular carcinoma after partial hepatectomy. Cancer. 1992;69:913-9.

3. Kim SU, Seo YS, Lee HA, et al. Hepatocellular carcinoma risk steadily persists over time despite long-term antiviral therapy for hepatitis B: a multicenter study. Cancer Epidemiol Biomark Prev. 2020;29:832-7.

4. Izumi R, Shimizu K, li T, et al. Prognostic factors of hepatocellular carcinoma in patients undergoing hepatic resection. Gastroenterology. 1994:106:720-7.

5. Koike Y, Shiratori Y, Sato S, et al. Risk factors for recurring hepatocellular carcinoma differ according to infected hepatitis virus-an analysis of 236 consecutive patients with a single lesion. Hepatology. 2000:32:1216-23.

6. Lise M, Bacchetti S, Da Pian P, et al. Prognostic factors affecting long term outcome after liver resection for hepatocellular carcinoma: results in a series of 100 Italian patients. Cancer. 1998:82:1028-36.

7. Poon RT, Fan ST, Lo CM, et al. Long-term survival and pattern of recurrence after resection of small hepatocellular carcinoma in patients with preserved liver function: implications for a strategy of salvage transplantation. Ann Surg. 2002;235:373-82. 
8. Wong L, Bozhilov K, Hernandez B, et al. Underlying liver disease and advanced stage liver cancer are associated with elevated neutrophillymphocyte ratio. Clin Mol Hepatol. 2019;25:305-16.

9. Yu LX, Ling Y, Wang HY. Role of nonresolving inflammation in hepatocellular carcinoma development and progression. NPJ Precis Oncol. 2018;2:6

10. Ringelhan M, Pfister D, O'Connor T, et al. The immunology of hepatocellular carcinoma. Nat Immunol. 2018;19:222-32.

11. Sachdeva M, Chawla YK, Arora SK. Immunology of hepatocellular carcinoma. World J Hepatol. 2015;7:2080-90.

12. Chew V, Chen J, Lee $D$, et al. Chemokine-driven lymphocyte infiltration: an early intratumoural event determining long-term survival in resectable hepatocellular carcinoma. Gut. 2012;61:427-38.

13. Wang $H$, Chen $L$. Tumor microenviroment and hepatocellular carcinoma metastasis. J Gastroenterol Hepatol. 2013;28(Suppl 1):43-8.

14. Gao B, Jeong WI, Tian Z. Liver: an organ with predominant innate immunity. Hepatology. 2008;47:729-36.

15. Peng H, Wisse E, Tian Z. Liver natural killer cells: subsets and roles in liver immunity. Cell Mol Immunol. 2016:13:328-36.

16. Caligiuri MA. Human natural killer cells. Blood. 2008;112:461-9.

17. Sung PS, Jang JW. Natural killer cell dysfunction in hepatocellular carcinoma: pathogenesis and clinical implications. Int J Mol Sci. 2018;19(11):3648.

18. Coulouarn C, Factor VM, Conner EA, et al. Genomic modeling of tumor onset and progression in a mouse model of aggressive human liver cancer. Carcinogenesis. 2011;32:1434-40.

19. Taketomi A, Shimada M, Shirabe K, et al. Natural killer cell activity in patients with hepatocellular carcinoma: a new prognostic indicator after hepatectomy. Cancer. 1998;83:58-63.

20. Cai L, Zhang Z, Zhou L, et al. Functional impairment in circulating and intrahepatic NK cells and relative mechanism in hepatocellular carcinoma patients. Clin Immunol. 2008;129:428-37.

21. Wu Y, Kuang DM, Pan WD, et al. Monocyte/macrophage-elicited natural killer cell dysfunction in hepatocellular carcinoma is mediated by CD48/2B4 interactions. Hepatology. 2013;57:1107-16.

22. Hoechst B, Voigtlaender T, Ormandy L, et al. Myeloid derived suppressor cells inhibit natural killer cells in patients with hepatocellular carcinoma via the NKp30 receptor. Hepatology. 2009;50:799-807.

23. Dessouki O, Kamiya Y, Nagahama H, et al. Chronic hepatitis C viral infection reduces NK cell frequency and suppresses cytokine secretion: reversion by anti-viral treatment. Biochem Biophys Res Commun. 2010;393:331-7

24. Ahlenstiel G, Edlich B, Hogdal $\perp$, et al. Early changes in natural killer cell function indicate virologic response to interferon therapy for hepatitis $C$. Gastroenterology. 2011;141(1231-1239):1239.e1231-1232.

25. Rey J, Anfossi N, Andre P, et al. Natural killer cells recovery after consolidation chemotherapy in elderly patients with acute myeloid leukemia (AML). In: American Society of Hematology; 2011.
26. Rey J, Fauriat C, Kochbati E, et al. Kinetics of cytotoxic lymphocytes reconstitution after induction chemotherapy in elderly AML patients reveals progressive recovery of normal phenotypic and functional features in NK cells. Front Immunol. 2017;8:64.

27. Kuang DM, Wu Y, Chen N, et al. Tumor-derived hyaluronan induces formation of immunosuppressive macrophages through transient early activation of monocytes. Blood. 2007;1 10:587-95.

28. Cheng J, Huo DH, Kuang DM, et al. Human macrophages promote the motility and invasiveness of osteopontin-knockdown tumor cells. Cancer Res. 2007;67:5141-7.

29. Kuang DM, Peng C, Zhao Q, et al. Tumor-activated monocytes promote expansion of IL-17-producing CD8+T cells in hepatocellular carcinoma patients. J Immunol. 2010;185:1544-9.

30. Kim T-H, Kim SY, Tang A, et al. Comparison of international guidelines for noninvasive diagnosis of hepatocellular carcinoma: 2018 update. Clin Mo Hepatol. 2019;25:245-63.

31. Kim Y-Y, Park M-S, Aljoqiman KS, et al. Gadoxetic acid-enhanced magnetic resonance imaging: hepatocellular carcinoma and mimickers. Clin Mol Hepatol. 2019;25:223-33.

32. Bruix J, Sherman M. Management of hepatocellular carcinoma: an update. Hepatology. 2011;53:1020-2.

33. Jung KS, Kim SU, Ahn SH, et al. Risk assessment of hepatitis B virus-related hepatocellular carcinoma development using liver stiffness measurement (FibroScan). Hepatology. 2011;53:885-94.

34. 2018 Korean Liver Cancer Association-National Cancer Center Korea Practice Guidelines for the Management of Hepatocellular Carcinoma. Korean J Radiol 2019;20:1042-1113.

35. Lencioni R, Llovet JM. Modified RECIST (mRECIST) assessment for hepatocellular carcinoma. Semin Liver Dis. 2010;30:52-60.

36. Forner A, Reig M, Bruix J. Hepatocellular carcinoma. Lancet. 2018;391:1301-14.

37. Vesely MD, Kershaw MH, Schreiber RD, et al. Natural innate and adaptive immunity to cancer. Annu Rev Immunol. 2011;29:235-71.

38. Juengpanich $S$, Shi L, Iranmanesh Y, et al. The role of natural killer cells in hepatocellular carcinoma development and treatment: a narrative review. Transl Oncol. 2019;12:1092-107.

39. Lee HA, Seo YS, Kim SU. Risk of hepatocellular carcinoma with tenofovir vs. entecavir in patients with chronic hepatitis B. Gastroenterology. 2020;158(8):2310-1

40. Kim SU, Seo YS, Lee HA, et al. A multicenter study of entecavir vs. tenofovir on prognosis of treatment-naïve chronic hepatitis B in South Korea. J Hepatol. 2019;71:456-64.

\section{Publisher's Note}

Springer Nature remains neutral with regard to jurisdictional claims in published maps and institutional affiliations.
Ready to submit your research? Choose BMC and benefit from:

- fast, convenient online submission

- thorough peer review by experienced researchers in your field

- rapid publication on acceptance

- support for research data, including large and complex data types

- gold Open Access which fosters wider collaboration and increased citations

- maximum visibility for your research: over 100M website views per year

At BMC, research is always in progress.

Learn more biomedcentral.com/submissions 